\title{
Technology Adoption and Value Chains in Developing Countries: \\ Evidence from Dairy in India
}

\author{
Emma Janssen $^{1}$ and Johan Swinnen ${ }^{1}$ \\ ${ }^{1}$ LICOS Centre for Institutions and Economic Performance
}

\begin{abstract}
Adoption of modern technologies in agriculture is crucial for improving productivity and welfare of poor farmers in developing countries. Not much is known about how value chains do (not) affect technology transfer and/or adoption in food chains in developing countries. We analyze farm-level technology adoption in the dairy chain in India, using unique survey data. The dairy chain in India is an important case because the Indian government has promoted development of the dairy sector for its potential for 'pro-poor' growth, and because value chain initiatives had strong effects on dairy farm technology in other countries with imperfect markets and growth in demand. We find that despite rapid growth in milk consumption and production, technology adoption in the form of better hygienic practices, better feed and improved livestock was mixed and low for certain regions and technologies. So far, the role of value chains in the dissemination of these technologies seems to be minor.
\end{abstract}




\section{Introduction}

The adoption of modern technologies in agriculture is essential to improve productivity and welfare of poor farmers in developing countries and is a key ingredient for achieving poverty reduction and rural development. However, the adoption of modern technology has been disappointing, particularly in the poorest agricultural regions of the world (Evenson and Gollin, 2003; Sheahan and Barrett, 2014). ${ }^{1}$

The role of value chains in technology adoption has not received much attention so far. A few studies have indicated that value chains can play a very important role in technology adoption, not just by processing companies, but also by farmers, through vertical coordination and spillover effects (Gow et al., 2000; Dries et al., 2009; Kuijpers and Swinnen, 2016).

Investments by modern processing and retailing companies typically include a modernization of procurement systems for sourcing high quality raw material, necessary to meet new consumer demands. An important aspect of this modernization process is the introduction of private standards to enhance quality of supplies and to overcome information asymmetry and reduce transaction costs. This often requires investments in new technologies by farmers, be it to improve productivity for minimum output, to upgrade product quality, or to satisfy other types of private standards. ${ }^{2}$ Many

\footnotetext{
${ }^{1}$ Explanations in the literature for the failure of technology adoption include imperfections in credit, information and labor markets: access to credit and information (Feder et al., 1985; Feder and Umali, 1993), the importance of learning trough social interactions or extension services (Cameron, 1999, Munshi, 2004, Bandiera and Rasul, 2006, Conley and Udry, 2010, Genius et al., 2013) and labor constraints (Moser and Barrett 2006).

${ }^{2}$ Most standards, codified or not, either directly or indirectly prohibit the use of less costly technology (Swinnen et al., 2015). In fact many of the most visible standards for consumers directly prohibit or require the use of certain inputs. Examples of commonly prohibited inputs are child labor, chemical inputs (in accordance with organic farming standards), or battery cages in the production of poultry. Examples of commonly required inputs are milk cooling equipment for dairy farmers and traceability systems for farmers supplying supermarket channels. Additionally, standards often require certain practices. For example GlobalGap certification requires Lychee farmers in Madagascar to use clean water for pre-harvest hand washing and to implement good picking and packaging practices for the transportation from the farm to the processing unit (Subervie and Vagneron 2013).
} 
studies have pointed at the challenges for small and poor farmers to satisfy these new requirements, and at the risk of further marginalization of this group (Reardon et al., 2003; 2009). However the same processes and forces, which impose new challenges on these farmers, may also be a force of innovation, technology transfer, and thus inclusion of this group.

With imperfect (or non-existing) technology markets, various forms of institutional innovations in value chains (such as vertically coordinated supply systems and interlinked contracting) have been introduced by up- and downstream companies to overcome constraints and enhance their access to and adoption of new technologies. This process of quality and technology upgrading has been documented and analyzed in transition countries (e.g. Gow et al., 2000; Dries and Swinnen, 2004, 2010) and in high-value supply chains in developing countries (eg. Minten et al., 2009). However, much less is known about how value chains do (not) affect technology transfer and/or adoption in domestic food chains in developing countries. In this paper we will contribute to our understanding of this by analyzing farm-level technology adoption in the dairy chain in India.

The dairy chain in India is a highly relevant case for several reasons. First, dairy production contributes to inclusive growth, especially in India where there is a high dependency of the poor on agriculture in terms of employment, and where dairy is a very important element. Agricultural production activities such as dairy, which are labor-intensive but do not overly rely on access to land or economies of scale, are generally expected to offer better prospects for income growth to the poorest rural households, often characterized by limited access to land, but easy access to cheap family labor. In fact, the Indian government has massively promoted development in the dairy sector for its potential for 'pro-poor' growth. For instance, the Operation Flood 
program was launched in 1970 with the objective of increasing milk production and income for small rural farmers; within 30 years it became one of the world's largest rural development programs. ${ }^{3}$

Second, value chain initiatives had dramatic effects on farm-level technology upgrading in the dairy sector in other countries which were characterized by (a) imperfect (or missing) credit and technology markets, (b) liberalization and growth in demand for (better quality) milk products. This was particularly the case in Eastern Europe in the 1990s, where significant investments by dairy processing companies triggered investments in improved technology by dairy farms, both large and small (Dries and Swinnen, 2004, 2010; Dries et al., 2009; Van Herck and Swinnen, 2015). Of course, there are differences between Eastern Europe in the 1990s and India today. A key difference is the level of income, which affects consumer demand. While incomes were much higher in Eastern Europe, they have been increasing significantly in India, creating a strong growth in demand for milk products (see Section 2). In addition, rapid urbanization and the spread of modern retail in India have contributed to a demand for high quality products and safety standards (Minten and Reardon, 2008; Reardon and Timmer, 2014). While demand growth over the past 20 years was initially mostly driving the need for higher quantities of milk supplies, more recently there has been increasing demand for better quality and safety of milk products (Squicciarini and Vandeplas, forthcoming). Hence, it remains an open question whether this growth in demand has translated into technology adoption in dairy farms.

The answer to this question is not just important from the Indian perspective, but has more general implications as it will provide insights in the nature of changes on

\footnotetext{
${ }^{3}$ India has also used these arguments in trade negotiations (both within the World Trade Organization (Jha, 2003) and in bilateral negotiations (Mondal et al., 2012)) to keep the dairy sector largely off the negotiation table (Goswami, 2007).
} 
the demand side that cause changes upstream in the value chain, and in particular technological improvements at the farm-level. Our analysis uses two sets of unique survey data of dairy value chains, one from Punjab and one from Andhra Pradesh. Dairy production is widespread in both regions, but Andhra Pradesh is dominated by smallholders while Punjab has a mix of smallholders and larger farms producing milk. This diversity can yield insights on technology adoption.

\section{Dairy and Technology in India}

\subsection{Dairy production and consumption}

India is the largest milk producing country in the world. It produced 155.5 million tonnes of milk in 2016 (National Dairy Development Board, 2017). The value of milk produced in India is 43 billion USD, more than the 38 billion USD for rice, India's major crop (FAO, 2012a). Figure 1 illustrates the impressive growth of Indian dairy production in the last decades. Strong income growth in India has led to higher levels of dairy consumption. In recent years, milk consumption has grown at an average rate of 6-8\% per annum (Rajeshwaran et al., 2014) and experts estimate that demand for milk and milk products will be growing even stronger at around $8-10 \%$ annually in the

coming years (VGBO, 2009). In addition, with increasing urbanization, Indian households increasingly rely on markets to buy milk, rather than keeping their own cows or buffaloes.

Dairy is a traditional activity in many regions of India. More than 70 million rural households produce milk. Our paper focuses on two important but quite different states of India: Punjab and Andhra Pradesh (AP). Punjab, in the North, is one of India's leading agricultural states and is the fourth largest milk producing state with a total production of 10.7 million tonnes in 2015-2016. Moreover, it had the highest per capita 
milk consumption within India (1032 grams/capita/day compared to a national average of 337 grams/capita/day (NDDB, 2017)). This is due to several factors: (1) favorable agro-climatic conditions (ensuring a high availability of green fodder), (2) a welldeveloped transport infrastructure that supports dairy commercialization, (3) a relatively high standard of living which pushes up local demand, and (4) extensive government support to the dairy sector (Chand, 1999; Staal et al., 2008). Dairy farm sizes are somewhat larger in Punjab than in the rest of India: the share of farmers with less than 2 ha of land in milk production was 39\% in Punjab while 69\% for India as a whole (Kumar et al., 2011).

AP is a fast-growing populous state in the south of India and is the third largest milk producing state, producing 10.8 million tonnes. AP experienced rapidly growing milk consumption per capita since milk consumption in AP grew by almost $30 \%$ over the past 5 years, to 475 grams/capita/day in 2015-2016. Milk buyers in AP frequently have shortages of raw milk, especially in summer (Squicciarini and Vandeplas, 2010). In AP, dairy production is mostly done by smallholders: approximately $80 \%$ of Andhra Pradesh's livestock population is owned by small and marginal farmers, as well as landless poor (Animal Husbandry Department Government of Andhra Pradesh, 2010).

\subsection{Milk quality}

Demand growth may provide incentives for adulteration. For example, excessive demand growth contributed to milk adulteration and major food safety problems (the "milk scandal") in China in the late 2000s (Mo et al., 2012). A series of food scandals in India in the early 2000s increased national awareness of safety concerns in the production, processing and marketing of food. This caused debates on 
the need to introduce safety and quality standards for milk. ${ }^{4}$ Yet, safety regulations have so far not been implemented. Anticipation regarding the impending implementation of the legislation - in conjunction with increasing pressure from consumers - may spur the emergence of private food standards in the Indian dairy industry. Interviews with dairy businesses in Andhra Pradesh revealed that Indian dairy processors decided to pursue different levels of Hazard Analysis and Critical Control Points (HACCP) and International Organization for Standardization (ISO) certification as a 'competitive' strategy, in an attempt to convince consumers that their milk is of high quality (Squicciarini and Vandeplas, 2010). A key question is how far these changes have spread along the value chain and to what extent these efforts are still confined to the processing level.

\subsection{Technology adoption in dairy production}

Increased demand and changes in consumer preferences following higher incomes could give the dairy sector incentives and means to invest in new technologies. Demand driven institutional innovations (in particular vertical coordination) have contributed to farm assistance programs by dairy processors to help farms invest in new technologies and improved milk quality and safety in other countries (see e.g. Dries et

\footnotetext{
${ }^{4}$ In 2006, Indian policy makers, pressured by civil society protests, drafted the Food Safety and Standards Act (FSSA). The Food Safety and Standards Authority of India (FSSAI) was established in 2011 to oversee the implementation of this Act. The Act determines which actor in the supply chain bears responsibility when food safety regulations are not complied with (Article 27 of FSSA 2006). For milk traders this implies that they will become liable for any adulterants (e.g., water, oil, skimmed milk powder, soda) added to the milk, even if the responsibility for adulteration lies with their suppliers unless they can specifically identify the culprit (Squicciarini and Vandeplas, forthcoming). These regulations extend to informal traders including street hawkers and itinerant vendors. Opponents of the Act claim that poor street vendors will be unable to comply with the food standards that have been imposed. While it was initially planned that the policy would come into effect on 5 August, 2012, this deadline has been repeatedly extended.
} 
al., 2009). In the Indian dairy context, improvement in technology and production practices relates to several elements.

First, milk quality can be enhanced by improving basic hygienic and food safety practices. Hygienic milking is important and includes washing of the hands, utensils, and udder and teats of dairy animals (DA) before and during milking (Kumar et al., 2011). At the same time, especially given India's climatic conditions, storage and preservation practices are essential to guarantee safe milk. Timely cooling of the milk is critical.

Second, an important area for increasing productivity is improving the quality of animal feed. Studies identify limited availability and affordability of quality feed as a major constraint to higher milk yields (Nagrale et al., 2015). The traditional diet of green and dry fodder should be enriched with concentrate feed to ensure the intake of sufficient protein, energy, minerals, and vitamins. Furthermore, these nutrients should be administered in amounts that match the physiological needs of the DA, which vary with status (pregnant, in milk, dry) and type (FAO, 2012b).

Third, another important technology to increase the yields are crossbred cows and graded buffaloes. The traditional DA in India are local (desi) cows and buffaloes with low milk yields. For cows, crossbreeding has been the main method to increase animal productivity. ${ }^{5}$ Crossbred cows are the result of inseminating local desi cows with a foreign cow breed (exotic) - usually the Holstein-Friesian (H.F.) and Jersey breeds. With proper feeding, they yield considerably more milk than local desi cows. For buffaloes, local types can be "graded up" with better breeds, usually of the Murrah

\footnotetext{
${ }^{5}$ Crossbreeding practices in India go back to as far as 1856 (Sinha, 1951) although the scaling up of this practice started only in 1963 with the introduction of the Intensive Cattle Development Project (ICDP) as part of the Special Development programme during the Third Five-Year Plan period (Rao et al., 1995). By 1982, 4.65\% of the DA population consisted of crossbred animals, but their prevalence differed across states (Livestock Census, 1982, as cited in Rao et al., 1995).
} 
type, which originate from Haryana and Punjab. While Murrah type buffaloes are not a technology adoption in Punjab, given that this breed is native to this state, they are in AP where graded buffaloes produce more milk than local buffaloes.

Ad hoc evidence and company interviews suggest that various improved practices and technologies are increasingly promoted to farmers by dairy companies. However, it is not clear how widespread improved technology adoptions are and whether their adoption is associated with specific value chains. In the remainder of this paper we use survey data from Punjab and AP to analyse the importance of these technological developments, and to study whether they are related to changes in value chains' institutional organization.

\section{Some Conceptual Issues and Hypotheses ${ }^{6}$}

Consider a simple value chain, which can include (in the downstream direction) input suppliers, farms, traders, processors, retailers, and final consumers. While goods flow downstream in the value chain, information and finance flow upstream. Information is important as farmers may need to adjust their production practices and technology when demand or consumer preferences change. Access to finance (in the form of own liquidity or loans) at each stage of this chain is crucial for technology investments by the various agents. Moreover, costs of technology investment are incurred at the start of the production cycle, while payment occurs at the end, making access to capital essential to bridge this gap. This is especially the case for farmers, where the duration of the production process may be relatively long or where long

\footnotetext{
${ }^{6}$ This section draws on more elaborate conceptual frameworks and theoretical models in Kuijpers and Swinnen (2016) and Swinnen et al (2015).
} 
term investments (such as animals) may only be paid for with small payments over time.

Hence, this form of technology adoption might not be working in the context of imperfect information systems and credit markets. It is well known that rural credit markets are often not working well in developing countries such as India (Banerjee and Duflo, 2014; Bardhan and Udry, 1999). Poor farmers may not have the financial means to make the investment out of own savings and may not get loans from banks or other lenders. Credit market imperfections will thus cause low technology adoption by farms (Feder et al., 1985).

Another reason for the farmer not to adopt the technology is when there is uncertainty about whether his investment will be rewarded. One possibility is buyer holdup at the time of delivery (Klein et al., 1978; Gow and Swinnen, 2001). Examples are late payments, renegotiation of prices at product delivery and the absence of transparent and reliable quality evaluation procedures (which could lead to inappropriately rejecting produce) (Barrett et al., 2012; Cungu et al., 2008; Saenger et al., 2014). For example, dairy farmers may not want to invest in better hygiene (financially or through extra effort) if they are not sure to get higher prices for improving milk quality or if improved quality cannot or is not measured. The failure to adopt the technology not only affects the farm, but the entire value chain. Dairy processors may not get the raw milk they need (either in terms of quantity or quality); and consumers may not get the products they desire. If so, dairy companies have an incentive to help the farm adopt the technology and they may have better access to finance. ${ }^{7}$ Dairy companies may also have better information on the required

\footnotetext{
${ }^{7}$ This may be because they have more liquidity, have better access to credit, because they can draw on other commercial activities, or because they face lower transaction costs. The latter can be the case when the firm provides the technology to multiple suppliers (e.g. as part of outgrower schemes or contracting systems) and benefits from economies of scale.
} 
technology (or production standards more generally) because they may have better knowledge of consumer preferences and government regulations.

Dairy companies can then consider whether it is profitable to set up different types of exchange systems (rather than spot markets) to source more or better quality milk from the farms. One element of such strategy is to invest in training and extension services to teach the suppliers (farmers) about better technologies and production practices. This may be part of (informal) contracting where companies invest in training specific (groups of) farmers who they source from. Such systems may also include farm-level inspections to see whether their suppliers practice what they are told. Another element of such contracting systems provide improved technology (or credit to purchase the technology) to their farms. Such interlinked contracts are well known in the traditional development literature for basic input provisions (Bardhan, 1989; Bell and Srinivasan, 1989). However, such contracts have been much more elaborate in modern dairy chains in emerging economies: they can include the provision of technical and management assistance, veterinary controls, access to quality animal feed, loans for purchasing better livestock, etc. (Dries et al., 2009).

A key problem with these contracts is to secure return on investment for the dairy companies. Companies may not want to make the investments if they expect that their competitors will benefit from the investments or that farmers will breach the contracts, for example by side-selling to other buyers. Problems with contract enforcement and supplier-buyer exclusivity are of particular concern when the company investment or contract risk is higher, and when competition for milk from other buyers is stronger. The companies' incentive to invest in such contracting systems are stronger when there is more demand for high quality dairy products, and thus more profit to be made from high quality milk. 
With rapidly growing (urban) demand for dairy products in a poor country such as India, our hypotheses are that such value chain initiatives for farm-level technology adoption (a) are emerging in sourcing from milk farmers; (b) are emerging first in the highest income regions; (c) are more prominent for yield enhancing technologies than for quality improvements, which may emerge only later when there is sufficient consumer demand for high quality dairy products; (d) initially focus on information and farming programs and farm-level inspections, and later on the provision of credit or direct technology as part of contracting.

\section{Data Collection}

We use two unique household-level datasets, covering the rural population of Punjab and for the southern half of AP, respectively. The Punjab data were collected in the summer of 2008. Punjab was divided into five regions. ${ }^{8}$ In each of these regions, one district was selected at random, with the probability of selection being proportional to the district's population share within that region, to avoid oversampling of households in smaller districts. All villages in these districts were stratified according to the marketing channels operating in that area, based on their appearance in a list of procurement villages provided by Nestlé and in a list of procurement villages provided by the respective milk unions if available, and otherwise on their proximity to cooperative sector cooling plants. We selected at random 15 'Nestlé' villages, 15 'cooperative' villages, 5 villages where both companies were expected to operate, and 15 villages where none of them were expected to operate. ${ }^{9}$ In each village, 20

\footnotetext{
8 The north-west (Amritsar and Gurdaspur), the north-east (Hoshiarpur, Jalandhar, Kapurthala and Nawanshahar), the south-west (Bathinda, Faridkot, Ferozepur, Moga and Muktsar), the south-east (Mansa, Patiala and Sangrur), and the central region (Fatehgarh Sahib, Ludhiana and Ropar).

${ }^{9}$ These 50 villages were spread over the 5 selected districts, resulting in a final selection of 6 villages in the district of Amritsar, 6 in Hoshiarpur, 14 in Ludhiana, 18 in Ferozepur, and 6 in Mansa.
} 
households were selected according to a stratified random sampling strategy based on a prior village census. More precisely, households were classified into categories based on the number of DA they owned (0 DA; 1-2 DA; 3-10 DA; >10 DA) and on the marketing channel to which they were selling milk. This sampling strategy allowed for oversampling of Nestlé and cooperative suppliers and large- and medium-size dairy farmers - as the majority of milk suppliers in Punjab have less than 3 DA. The setup of the sample allows extrapolation to the level of the state of Punjab, by using the appropriate weighing factors.

The AP data were collected between April and June $2010 .{ }^{10}$ First, the study region was subdivided into four zones based on milk production per rural capita, and buffalo or cow-based dairy production systems, which may correlate with weather and relative humidity conditions. Within each region, one district was sampled at random. In the selected districts, 50 rural villages were randomly selected ${ }^{11}$. In each village, a census was organized to record the number of female adult DA each household owned. Based on this number, households were classified into four categories. As such, we obtained a sample of 1,000 households in both Punjab and AP. The selected households were surveyed in detail about their general characteristics, their income-generating activities and expenditures, and in particular on dairy production practices and use of input and output markets. Moreover, we collected recall data on a series of variables to study the most important dynamics of the sector.

\footnotetext{
${ }^{10}$ The survey covers Rayalaseema (in particular, the districts Kurnool, Cuddapah, Ananthapur, and Chittoor) and the southern part of Coastal Andhra (more specifically the districts Nellore, Prakasam, Guntur, and Krishna).

${ }^{11}$ (of which 7 in Chittoor, 12 in Cuddapah, 16 in Kurnool, and 15 in Guntur) from the district-level list of villages which was obtained from the Government of AP (Government of Andhra Pradesh, 2009).
} 


\section{Milk Procurement Structure and the Value Chain}

Figures 2 and 3 and Table 1 document the structure of the dairy supply chains in Punjab and AP respectively. There are three main outlets. First, a major portion of the milk produced was for home consumption or sold informally, either directly to neighbors or friends, or to informal milk traders (dudhiyas). These dudhiyas pick up the milk from the household's $(\mathrm{HH})$ doorstep and directly market it to other $\mathrm{HH}$ within the (neighboring) village(s). In Punjab, $26.4 \%$ of the dairy farmers and $28.4 \%$ in AP did not sell any milk or sold only directly to neighbors. Informal milk traders were the main buyers for $11.9 \%$ of the HH with DA in Punjab and $23.5 \%$ in AP.

Second, traditionally cooperatives bought surplus milk from farms (Cunningham, 2010). In Punjab, the cooperative sector is mainly represented by the Punjab State Cooperative Milk Producers Federation Ltd., popularly known as Milkfed - or by its brand name, Verka. In AP, all the district-level cooperatives used to be part of the APDDCF (Andhra Pradesh Dairy Development Cooperative Federation Ltd). Around 2002, nine of these district-level cooperatives declared their independence from the government and are now called MACS (Mutually Aided Cooperative Societies), but the general organizational structure of these MACS remains largely the same. Milk procurement by cooperatives in both Punjab and AP is organized through village-level collection centers. Dairy farmers can bring their milk to these centers. In our sample, $22.7 \%$ of the dairy farmers in Punjab and $28.7 \%$ in AP supplied to the cooperative channel.

Third, the de-licensing of dairy companies in 1991 allowed private firms to enter the dairy value chain. In Punjab, private dairy companies buy milk from farmers either through private milk buyers or milk collection centers. In AP, private companies usually source their milk through private milk buyers who either pick up the milk from 
the farmers' doorstep or have their own collection center (Squicciarini and Vandeplas, 2010). In our sample, $39 \%$ of the dairy farmers in Punjab sold to private dairy companies, with $15.2 \%$ selling to domestic companies and $23.8 \%$ selling to the multinational Nestlé who has a longstanding tradition of milk procurement in Punjab.

In Punjab, larger commercial dairy farmers often directly supply to processing plants (cooperatives, Nestlé or domestic private companies) and their milk is collected on the farm by the dairy companies. In AP, at the time of the survey, larger scale commercial dairy farming was still very scant, so direct procurement by processing companies from farmers was uncommon.

Interestingly, and importantly from the perspective of value chain developments as discussed earlier, we did not find any evidence of contracts (not even oral agreements) between dairy farmers and milk buyers in either Punjab or AP. This suggests the absence of vertical coordination in the Indian dairy value chains at the time of the surveys.

\section{Technology Adoption}

\subsection{Better hygienic practices}

Table 2 summarizes hygienic practices in Punjab and AP. While the vast majority of the households washed their hands before milking, in AP only very few (5\%) repeated this action in between milking different animals. This increases the likelihood of transmitting infections between DA. In Punjab 56.6\% of the households washed their hands in between milking different DA. Most households only used water to wash their hands: less than 5\% used soap in AP and around $15 \%$ in Punjab. In almost all cases udder and teats were washed before milking (only with water), to remove mud, dust and dung, but udder and teats were dried only by $14 \%$ (Punjab) and 25\% (AP). This increases the probability of contamination of the milk and exposes the udder and/or 
teats to infections (mastitis). Most households (96\% in Punjab and 92\% in AP) washed their utensils at least once a day, usually with water only (60\% in AP and $81 \%$ in Punjab).

The time between milking and cooling the milk to an appropriate temperature is crucial, since in this moment the microbial content of the milk grows exponentially. The main strategy of the households was to sell the milk as soon as possible after milking. Around $80 \%$ of the households did not treat (cool, boil, etc.) the milk before selling it in Punjab (no data for AP). Most milk producers sold their produce almost directly after milking. More than $90 \%$ stored their milk for 30 min. or less on the farm and almost $60 \%$ for 15 min. or less.

Dairy company incentives also seemed to be limited to minimize time between milking and cooling by investments in collection centers close to the farmers. The organization of the value chain in both Punjab and AP allows for close contact between milk buyers and dairy farmers and this could serve as a vehicle for information distribution at a relatively low cost. However, in Punjab only $1 \%$ of the dairy farmers ever received information in some form regarding hygienic milk production and in AP only $3.3 \%$ (Table 3 ).

Safety and quality inspections were also very limited. In Punjab, $13.7 \%$ of the dairy farmers were visited for inspection (5.3\% was inspected by their milk buyer and $5.6 \%$ by the government). In AP only $0.3 \%$ of the dairy farmers were inspected. In summary, value chain initiatives have focussed on investment in village milk collection centers but not in providing information and incentives for adoption of better hygienic practices, nor in organizing inspections at the farm level. 


\subsection{Better feed}

Table 3 indicates that improved feeding practices $^{12}$ through the use of compound/mixed concentrated feed were far more common in Punjab (54\%) than in $\mathrm{AP}(8 \%)$. This clearly indicates that in both regions, and especially in AP, there is much room for improving milk yields through better feed.

Value chains could improve the accessibility of good quality compound/mixed concentrated feed and provide training regarding the choice of feed to make up a balanced diet. From our company interviews in Punjab and AP, it appeared that most dairy firms offered compound/mixed concentrated feed to their farmers at production costs, that some provide subsidized feed and that some offer it for free.

However, the farm-level data present a different picture. In Punjab, $49.5 \%$ of the dairy farmers purchased compound/mixed concentrated feed ${ }^{13}$ of which $12.8 \%$ got it from Nestlé ${ }^{14}, 7.3 \%$ bought it from a cooperative and $4.3 \%$ from a private dairy. The majority (29.1\%) still bought the feed from a general store (Table 3). In AP, only 6.6\% of the dairy farmers purchased compound/mixed concentrated feed and only $0.6 \%$ bought it from their milk buyer. 5.1\% purchased it from a private shop.

$11.4 \%$ of all dairy farmers indicated that their buyer was offering subsidized compound/mixed concentrated feed but only $4.8 \%$ used this service in the past. $5.9 \%$

\footnotetext{
${ }^{12}$ In our survey, we distinguished between 4 different types of concentrate feed: a) grains and grain bran, b) oilseeds and oilcakes, c) compound/mixed cattle feed, and finally d) other concentrates, which includes salts and mineral mixtures. While grains, oilseeds/oilcakes, and salts/mineral mixtures are all part of a balanced diet, the compound/mixed concentrates usually contain all these elements and is therefore the best indicator for whether a household has adopted enhanced feeding practices. Moreover, different compositions of compound feed that are mixed in such way that fulfill the requirements of different types of animals (crossbred/desi) as well as match the status of the DA (pregnant, in milk, dry) can be purchased (if available). Some dairy farmers also mix their own concentrates.

${ }^{13}$ Note that some farmers mix their own compound/mixed concentrates and therefore, the number of dairy farmers that purchases this type of concentrates is lower than the number of dairy farmers that uses it.

${ }^{14}$ Nestlé is producing its own brand of concentrate feed.
} 
said that their buyer was offering free concentrate feed but only $2 \%$ used this service. The main reason appears to be that the feed quality was not good.

Apart from enhancing the availability of concentrates, companies can assist in increasing yields by informing households of the benefits of feed practices and training them in using proper quantities and ratios. In Punjab, only $1.1 \%$ ever got training/advice. In AP, only $3.9 \%$ got some sort of advice/training (and less than $1 \%$ from their milk buyers).

In summary, around $50 \%$ of the farmers used compound/mixed concentrated feed in Punjab, but less than $10 \%$ in AP. Dairy companies claimed that they were increasingly providing such feed to their farmers, often at subsidized prices. However, according to our survey, very few farmers bought or used compound/mixed concentrated feed from the companies. In addition, there was virtually no training or information offered on the potential benefits of (better) compound/mixed concentrated feed.

\subsection{Better animals}

The adoption of more productive animals was also much higher in Punjab than in AP. Official statistics indicate that by 2012, $85 \%$ of the cows in Punjab were crossbred (Table 4). The majority of the DA population (68\%) in Punjab were buffaloes, which were all Murrah or Murrah graded, as this is the local breed. Our survey data are consistent with this, and even indicate a higher share of crossbred cows. Both data sources indicate that more than $90 \%$ of the DA were graded and crossbreds.

The situation is very different in AP. Official statistics as well as our survey data put the share of crossbred cows at only $33 \%$ and the share of graded buffaloes 
around $30 \%$. This makes that in AP around $70 \%$ of DA were still low yielding DA types, compared to less than $10 \%$ in Punjab.

In both regions there have been significant increases in the number of DA and in the number of improved DA. However, again there are important differences between regions (Table 5). In Punjab, both the number of cows and the number of buffaloes increased by $12 \%$, and all of the new animals were high-yielding animals. In AP, the total number of animals increased by $24 \%$, double the increase of Punjab. However, while there was a strong expansion of the number of graded buffaloes $(+70 \%)$, most of the increase in cows was in desi cows $(+43 \%)$, not in crossbred cows $(+4 \%)$. Interviews with milk farmers suggested that the reason was that crossbred cows were much more vulnerable to hot and dry weather conditions in AP than desi cows. This was less of a problem with graded buffaloes, which were graded up with local Indian breeds.

The value chains' role in stimulating adoption of more productive animals again seems limited (Table 3 Panel E and F). In Punjab, only 1\% and in AP 3.6\% of the dairy farmers indicated that they ever got advice/training on the choice of breed.

Value chain finance for investing in better animals was completely absent. In Punjab, very few households took a loan for buying any type of cow and there was not a single household that used a loan to finance the purchase of a crossbred cow. In AP, less than $5 \%$ of the dairy farmers bought a graded buffalo or a crossbred cow that was at least partly financed by a loan. Only 1 household got credit from a cooperative.

\subsection{Summary}

Our data suggest that adoption rates varied across technologies and across the two states. In both Punjab and AP, there is room for improvement regarding hygienic 
practices. Compound feed was used by approximately half the farmers in Punjab, but much less in AP. The adoption rate of graded/crossbred cattle was high in Punjab but much lower in AP, where only about $1 / 3^{\text {rd }}$ of the dairy farmers owned at least one graded/crossbred DA.

While company interviews suggest that dairy companies actively supported better technology adoption at the farms, our farm surveys suggest that this was not (yet) the case. For all technologies and both states, the value chains seemed to have played a very minor role in promoting hygienic practices, fostering the use of concentrates, or encouraging the purchase of higher yielding cattle.

\section{Profile and Value Chains of Technology Adopters : Econometric Analysis}

To get further insights into which farmers had adopted the technologies and whether this was correlated with specific value chains, we use three indicators of adoption: an index of good hygienic practices ${ }^{15}$, a dummy indicating the use of compound/mixed concentrates, and the share of graded/crossbred DA in total herd size.

Table 6 shows that there was little correlation between the indicators. In Punjab, the share of graded/crossbred DA in total herd size was weakly (0.13) associated with the use of compound/mixed concentrated feed, but not related to better hygienic practices. In AP, dairy farmers with a higher share of graded/crossbred DA in terms of their total herd size were observed to have lower scores on the hygiene index $(-0.16)$. This suggests that adoption of one technology did not imply the adoption of the other

\footnotetext{
${ }^{15}$ We use an index measuring the extent to which farmers adhere to the different hygienic practices. More precisely, answer categories are ranked from least hygienic to most hygienic practice (best practice). In all cases, 0 means no compliance. Some indicators (e.g. mode of washing) allow for intermediate categories which signal partial compliance to best practices. To obtain the degree of compliance for each practice, we divide the rank of the answer category by the total number of answer options minus 1 . This gives us a number between 0 and 1 for each hygienic practice. We assign equal weights to each practice and therefore obtain the index by taking the average of the compliance levels for the individual indicators.
} 
technologies. This is somewhat surprising because the benefits from investments in graded/crossbred DA hinges on appropriate feeding practices, and because we would expect that entrepreneurial farmers would lead adoption on all three technologies.

To measure the correlation between technology adoption and farmer's socioeconomic characteristics and link to specific value chains, we use an econometric analysis $^{1617}$. The model is specified as follows:

$$
y_{i, j}=\alpha+\beta C_{i, j}+\delta H S_{i, j}+\theta X_{i, j}+\mu D_{j}+\varepsilon_{i, j}
$$

where $y_{i, j}$ is the adoption indicator, $C_{i}$ is a set of dummies indicating the channel through which the household was selling its milk, $H S_{i, j}$ is a vector of variables related to farm size and income, and $X_{i, j}$ is a vector of other household characteristics (the results are listed only for age, education and caste but we included more control variables ${ }^{18}$ ). Finally, $D_{j}$ is a set of dummies controlling for district-level effects and $\varepsilon_{i, j}$ is the error term. Although this model does not tackle various self-selection and endogeneity issues, it can still provide useful (conditional) correlations.

The results are shown in Tables 7 and 8 . In terms of correlations of value chains with technology adoption, the general conclusion is that there were only few significant correlations. We do observe that in Punjab farms that supplied to Nestlé were more likely to have adopted technologies than those who sold to informal buyers (the base category). However, the causality is not clear: households may have invested more because they sold to Nestlé or Nestlé may have preferred to source from better farmers. In AP, supplying to cooperatives was associated with less graded/crossbred DA and

\footnotetext{
${ }^{16}$ For raw correlations of income with our technology adoption indicators, see Table A1 in our online appendix. In short we find very low (but mostly positive) correlation coefficients.

${ }^{17}$ For a further decomposition of the correlations between these socio-economic characteristics and the technology adoption indicators, see Tables A2-A3 for the hygiene index, Tables A4-A5 for concentrate feed and Tables A6-A7 for number of graded/crossbred DA.

${ }^{18}$ We also control for the number of household members over 55, whether the household head's parents were already producing milk, whether the household is Sikh (in Punjab) or Muslim or Christian (in AP).
} 
households that did not sell milk had lower hygienic standards. Again, one should be careful in drawing conclusions: households may have invested less in hygiene since they were not selling the milk, or they may not have been able to sell the milk because their hygienic standards were too low.

The correlations between technology adoption and household characteristics also indicate important differences between the two regions. In Punjab, higher technology adoption was associated with larger herd sizes, while this was not the case in AP. Income from dairy was positively correlated with all forms of technology adoption in AP, but not in Punjab. Again, the causality of this positive relationship may run both ways: farmers may have gotten higher income from milk production because they used better technologies, or they many have invested because they got higher incomes from dairy. In Punjab there were no significant correlations with other household characteristics while in AP younger farmers used better hygienic technology and the share of improved animals was higher among more educated farmers, but also among older and lower caste farmers.

In summary, while it is important to emphasize again that these correlations should be interpreted with care because of possible self-selection and endogeneity issues, the fact that there were few significant correlations of technology adoption with the value chains and the fact that the estimated coefficients are generally small is consistent with our conclusions from the previous sections that value chains have had limited effects on technology adoption.

\section{Conclusions}

Adoption of modern technologies in agriculture can be crucial for improvement of the productivity and welfare of poor farmers in developing countries and the value 
chains can play a crucial role in fostering the adoption of new technology, by spreading information and supporting the modernization of procurement systems. While this process has been analyzed in emerging countries and in high-value supply chains in developing countries, little is known about how value chains do (not) affect technology transfer and/or adoption in domestic food chains in developing countries.

In this paper we analyzed the impact of value chains on farm-level technology adoption in the dairy chain in India. There has been very strong growth in dairy production and consumption in India over the past two decades. Dairy products are a major part of Indian diets and milk production is a major production activity for many poor Indian farmers. Our analysis relies on two sets of unique and survey data from Punjab and Andhra Pradesh, two states with an important dairy sector, but also with important differences as Punjab is more developed than AP.

Our analysis indicates that there were significant differences in improved agricultural technology adoption, in the form of hygienic practices, better feed and higher-yielding livestock. In general, technology adoption was much higher in Punjab than in AP. For example, around $50 \%$ of the farmers used compound/mixed concentrated feed in Punjab, but less than $10 \%$ in AP. Although there had been significant investments in cows and buffaloes in the years before the surveys, low yielding animals still accounted for around $70 \%$ of dairy animals in AP, while less than $10 \%$ in AP.

We also find that at the time of the surveys (2008/2010) value chains had not played a major role in stimulating technology adoption by dairy farms. Dairy companies had invested in collection centers in villages to reduce the time between milking and cooling, but had invested hardly anything in training or extension programs to improve farmers' hygienic practices, or in farm-level inspections. 
While dairy companies claimed that they were increasingly providing such feed to their farmers, often at subsidized prices, our survey indicates that very few farmers bought or used compound feed from the companies. In addition, there was virtually no training or information offered on the potential benefits of better compound/mixed concentrated feed.

Similarly, while there have been significant investments in animals, value chain advice or finance seems to have played a very limited role. In the 5 years before the survey, the DA in Punjab grew by $12 \%$ (all high-yielding) and in AP by $24 \%$ (mostly high-yielding buffaloes and low-yielding cows), but dairy companies did not play a role in this.

These observations indicate that despite the increased demand for milk, this had not (yet) triggered important institutional innovations in the value chains at the time of our surveys. One explanation is that the increased demand was mostly for existing dairy products which did not require significant quality investments which in turn had not induced more extensive quality monitoring (including investments in better and personalized quality testing). The latter could trigger stronger demands for on-farm investments and closer farm-processor links. Another explanation is that the existing infrastructure (and the absence of institutions and infrastructure for testing) made it very costly to invest in upgrading supply systems for dairy companies. In addition, the availability of many milk sales channel options for farmers (both formal and informal) made it very costly to enforce potential supplier contracts. In combination these factors may explain the absence of value chain initiatives in the dairy chain by 2010 .

This may change if demand keeps growing and in particular if there would be a substantive shift towards higher quality and higher value dairy products (leading to more stringent private standards for at least part of the dairy system), or if the 
introduction of government safety and quality regulations would require important changes in milk production and processing systems (leading to more stringent public standards for potentially the entire dairy system). This would require important investments in monitoring and guaranteeing of more stringent public and private standards, possibly triggering important changes throughout the value chain and more significant value chain impacts on farm-level technology adoption. 


\section{References}

Animal Husbandry Department Government of Andhra Pradesh (2010) "Integrated Sample Survey: Estimates Of Major Livestock Products For The Years 2008-2009 \& 2009-2010 (Provisional) And Veterinary Infrastructure Facilities" Animal Husbandry Department Government of Andhra Pradesh

Banerjee, A. V., and E. Duflo (2014) "Do Firms Want to Borrow More? Testing Credit Constraints Using a Directed Lending Program." The Review of Economic Studies 81 (2): 572-607.

Bandiera, O. and I. Rasul (2006) "Social Networks and Technology Adoption in Northern Mozambique.” The Economic Journal, 116(514): 869-902

Bardhan, P. (1989) The Economic Theory of Agrarian Institutions Clarendon. Oxford.

Bardhan, P. and C. Udry (1991) Development Microeconomics. Oxford University Press

Barrett, C. B., Maren E. B., M. F. Bellemare, H. C. Michelson, S. Narayanan, and T. F. Walker (2012) "Smallholder Participation in Contract Farming: Comparative Evidence from Five Countries." World Development 40 (4): 715-30.

Bell, C. and T. N. Srinivasan (1989) "Interlinked Transactions in Rural Markets: An Empirical Study of Andhra Pradesh, Bihar and Punjab." Oxford Bulletin of Economics and Statistics 51 (1): 73-83.

Cameron, L. A. (1999) "The Importance of Learning in the Adoption of High-yielding Variety Seeds." American Journal of Agricultural Economics, 81, (1): 83-94

Chand, R. (1999) "Emerging crisis in Punjab agriculture: Severity and Options for future." Economic and Political Weekly, 34(13): A2-A10.

Conley, T. G. and C. R. Udry (2010) "Learning About a New Technology: Pineapple in Ghana." The American Economic Review, 100(1): 35-69.

Cungu, A., H. Gow, J. F. M. Swinnen, and L. Vranken (2008) "Investment with Weak Contract Enforcement: Evidence from Hungary during Transition." European Review of Agricultural Economics 35 (1): 75-91.

Cunningham, K. (2010) "Rural and Urban Linkages: Operation Flood's Role in India's Dairy Development.” IFPRI discussion paper 00924.

DAHDF (2012a) "Basic Animal Husbandry Statistics". Department of Animal Husbandry, Dairying and Fisheries. Ministry of Agriculture, Government of India. Krishi Bhawan, New Delhi, India.

DAHDF (2012b) "19th Livestock Census: All India Report". Department of Animal Husbandry, Dairying and Fisheries. Ministry of Agriculture, Government of India. Krishi Bhawan, New Delhi, India.

Das, A. (2006) "WTO Negotiations and India's Stand: Agriculture, NAMA and Services." 
Dries, L., E. Germenji, N. Noev, and J. F. M. Swinnen (2009) "Farmers, Vertical Coordination, and The Restructuring of Dairy Supply Chains in Central and Eastern Europe.” World Development, 37 (11): 1742-1758.

Dries, L. and J. F. M. Swinnen (2004) "Foreign Direct Investment, Vertical Integration, and Local Suppliers: Evidence from the Polish Dairy Sector." World Development, 32(9): 1525-1544

Dries, L. and J. F. M. Swinnen (2010) "The Impact of Interfirm Relationships on Investment: Evidence from the Polish Dairy Sector.” Food Policy, 35 (2): 121-129.

Evenson, R. E. and D. Gollin (2003) "Assessing the Impact of the Green Revolution, 1960 to 2000." Science, 300(5620):758-62

FAO (2012a). Faostat. Available at: http://faostat.fao.org.

FAO (2012b) "Balanced feeding for improving livestock productivity - Increase in milk production and nutrient use efficiency and decrease in methane emission", by M.R. Garg. FAO Animal Production and Health Paper No. 173. Rome, Italy

Feder, G., R. E. Just, and D. Zilberman (1985) "Adoption of Agricultural Innovations in Developing Countries: A Survey." Economic development and cultural change, 33 (2), 255-298.

Feder, G. and D. Umali (1993) “ The Adoption of Agricultural Innovations: A Review.” Technological Forecasting and Social Change, 43: 215-239.

Genius, M., P. Koundouri, C. Nauges and V. Tzouvelekas (2013) "Information Transmission in Irrigation Technology Adoption and Diffusion: Social Learning, Extension Services and Spatial Effects." American Journal of Agricultural Economics, 96(1): 328-344.

Goswami, B. (2007) "Can Indian Dairy Cooperatives Survive in the New Economic Order?" Paper presented at the WTO Public Forum "How Can the WTO Help Harness Globalization", Geneva, Switzerland.

Gow, H. R., and J. F. M. Swinnen (2001) "Private Enforcement Capital and Contract Enforcement in Transition Economies." American Journal of Agricultural Economics 83 (3): 686-90.

Gow, H. R., D. H. Streeter and J. F. M. Swinnen (2000) "How Private Contract Enforcement Mechanisms Can Succeed Where Public Institutions Fail: The Case Of Juhocukor A.S.” Agricultural Economics. 23(3): 253-265

Jha, B. (2003) "India's Dairy Sector in the Emerging Trade Order" IEG Working Paper $\mathrm{E} / 243 / 2004$.

Klein, B., Robert G. C., and A. A. Alchian (1978) "Vertical Integration, Appropriable Rents, and the Competitive Contracting Process." The Journal of Law \& Economics 21 (2): 297-326.

Kuijpers, R., and J. F. M. Swinnen (2016) "Value Chains and Technology Transfer in Emerging and Developing Countries." Working Paper. 
Kumar, A., S. J. Staal, and D. K. Singh (2011) “Smallholder Dairy Farmers' Access to Modern Milk Marketing Chains in India." Agricultural Economics Research Review, 24: $243-253$

Kumar, A. , I. A. Wright and D. K. Singh (2011) “Adoption of Food Safety Practices in Milk Production: Implications for Dairy Farmers in India.” Journal of International Food \& Agribusiness Marketing, 23:4: 330-344,

Minten, B. and T. Reardon (2008) "Food Prices, Quality, and Quality's Pricing in Supermarkets vs Traditional Markets in Developing Countries." Review of Agricultural Economics, 30(3): 480-490.

Minten, B., T. Reardon and A. Vandeplas (2009) "Linking Urban Consumers and Rural Farmers in India: A Comparison of Traditional and Modern Food Supply Chains." IFPRI discussion papers 883, International Food Policy Research Institute (IFPRI).

Mo, D., J. Huang, X. Jia, H. Luan, S. Rozelle and J. F. M. Swinnen (2012) "Checking into China's cow hotels: have policies following the milk scandal changed the structure of the dairy sector?" Journal of Dairy Science, 95(5): 2282-2298

Mondal, B., S. Sirohi, and V. Thorat (2012) "Impact of ASEAN-India Free Trade Agreement on Indian Dairy Trade: A Quantitative Approach.” MPRA working paper 40790.

Moser, C. M. and C. B. Barrett (2006.) "The Complex Dynamics of Smallholder Technology Adoption: The Case of SRI in Madagascar." Agricultural Economics, 35(3): 373-388.

Munshi, K. (2004) "Social Learning in a Heterogeneous Population: Technology Diffusion in the Indian Green Revolution." Journal of Development Economics, 73(1): $185-213$

Nagrale, B. G., K. K. Datta and A. K. Chauhan (2015) "An Analysis of Constraints Faced by Dairy Farmers in Vidarbha Region of Maharashtra." Indian Journal of Dairy Science, 68(4)

National Dairy Development Board (2017) Statistics available at http://www.nddb.org/information/stats/milkprodindia. Accessed on 03/04/2017

Rajeshwaran, S., G. Naik, and A. C. Dhas, (2014) "Rising Milk Price - A Cause for Concern on Food Security.” IIM Bangalore Research Paper No. 472.

Rao, S. V. N., V. Venkatasubramanian, and J. De Wit (1995) "Consequences of Crossbreeding Programme in India." Economic and Political Weekly, 30(39): A11216.

Reardon, T., C. B. Barrett, J. A. Berdegue, and J. F. M. Swinnen (2009) "Agrifood Industry Transformation and Small Farmers in Developing Countries." World Development, 37(11), 1717-1727.

Reardon, T. and C. P. Timmer (2007) "Transformation of Markets for Agricultural Output in Developing Countries Since 1950: How Has Thinking Changed?.” Chapter 
55 in R.E. Evenson, and P. Pingali (eds.). Handbook of Agricultural Economics, 3: Agricultural Development: Farmers, Farm Production and Farm Markets. Amsterdam: Elsevier Press: 2808-2855

Reardon, T. and C. P. Timmer (2014) "Five Inter-Linked Transformations in the Asian Agrifood Economy: Food Security Implications." Global Food Security, 3(2)

Saenger, C., Maximo T., and M. Qaim (2014) "Impact of Third-Party Contract Enforcement in Agricultural Markets-A Field Experiment in Vietnam." American Journal of Agricultural Economics, May.

Sheahan, M. and C. B. Barrett (2014) "Understanding the Agricultural Input Landscape in Sub-Saharan Africa: Recent Plot, Household, and Community-Level Evidence." SSRN Scholarly Paper ID 2487612. Rochester, NY: Social Science Research

Sinha, B. N. (1951) “Taylor cows of Patna.” Indian Veterinary Journal. 27: 272-276.

Staal, S. J., Nin Pratt, A., Jabbar, M. (2008) Dairy development for the resource poor. Part 3: Pakistan and India Dairy Development Case Studies. PPLPI Working paper No.44-3, International Livestock Research Institute and Food and Agriculture Organization of the United Nations.

Subervie, J. and I. Vagneron (2013) "A Drop of Water in the Indian Ocean? The Impact of GlobalGap Certification on Lychee Farmers in Madagascar." World Development, 50: $57-73$

Swinnen, J. F. M., K. Deconinck, T. Vandemoortele and A. Vandeplas (2015) Quality Standards, Value Chains and International Development. New York, USA: Cambridge University Press.

Squicciarini, M. and A. Vandeplas (2010) "The Dairy Sector of Andhra Pradesh: Findings from a Company Survey" No. TAPSIM deliverable D5.3, LICOS, KU Leuven, Belgium.

Squicciarini, M. and A. Vandeplas (forthcoming) "Food Safety Standards for Domestic and International Markets: The Case of Dairy". In: Brouwer, F., Joshi, P.K. (eds.) International trade and poverty; the future of Indian agriculture . Oxfordshire: CABI Publications

Van Herck, K. and J. F. M. Swinnen (2015) "Small farmers, Value Chains, and Structural Change: Panel Evidence from Bulgaria." British Food Journal, 117 (10), 2435-2464.

VGBO (Victorian Government Business Office-India) (2009) Market Opportunities in Indian Dairy Value Chain. A research study for the VGBO. Department of Business and Innovation, Australia. 


\section{FIGURES}

Figure 1: Milk production in India (Million Tonnes)

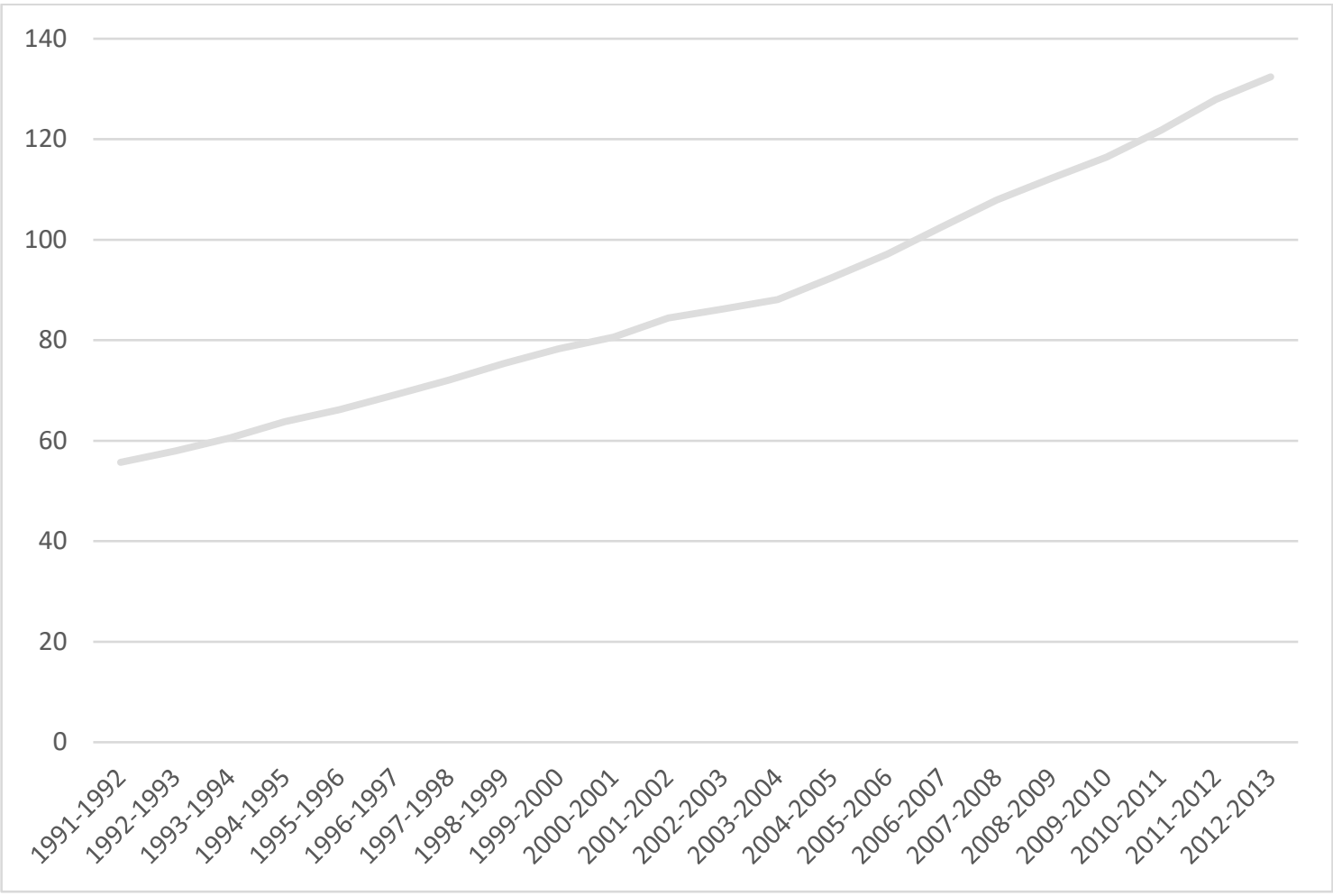

Source: National Dairy Development Board (2016) 
Figure 2: Milk procurement structure in Punjab

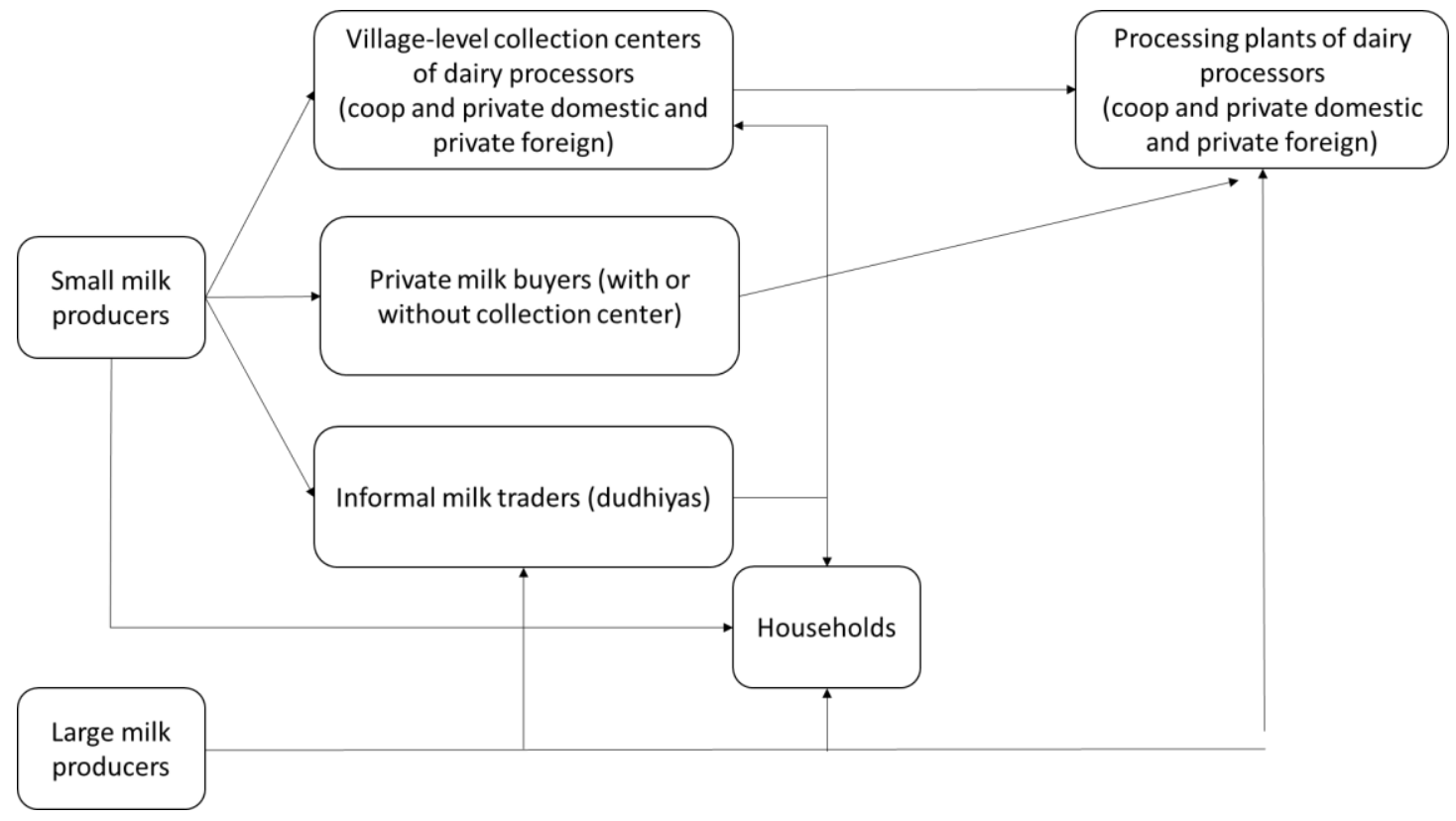

Figure 3: Milk procurement structure in AP

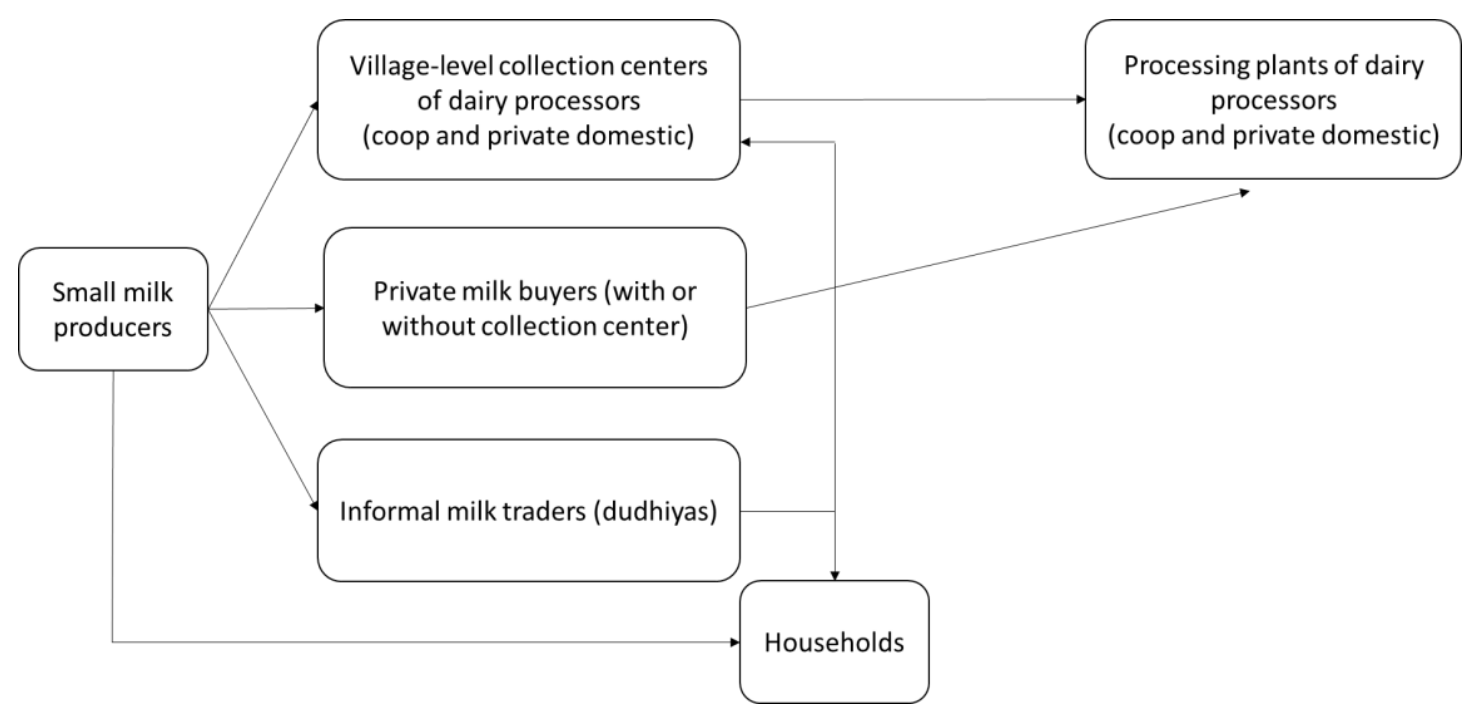


TABLES

Table 1: Main channel of milk sales (\% of $\mathrm{HH}$ in sample)

\begin{tabular}{llcc}
\hline & & Punjab & AP \\
\hline A. Cooperative & & $22.7 \%$ & $28.7 \%$ \\
B. Private & domestic & $15.2 \%$ & $19.4 \%$ \\
& foreign & $23.8 \%$ & $0 \%$ \\
C. Informal & households & $2.2 \%$ & $9.5 \%$ \\
& informal milk traders & $11.9 \%$ & $23.5 \%$ \\
D. No sales & & $24.2 \%$ & $18.9 \%$ \\
\hline \hline
\end{tabular}




\begin{tabular}{|c|c|c|}
\hline & Punjab & AP \\
\hline \multicolumn{3}{|l|}{ Panel A: Hygienic practices } \\
\hline \multicolumn{3}{|l|}{ Cleaning of hands } \\
\hline \multicolumn{3}{|l|}{ Are the hands washed? } \\
\hline Never & $4 \%$ & $2 \%$ \\
\hline Only before milking & $39.4 \%$ & $93 \%$ \\
\hline In between & $56.6 \%$ & $5 \%$ \\
\hline \multicolumn{3}{|l|}{ Mode of washing hands? } \\
\hline No hand washing & $4 \%$ & $2 \%$ \\
\hline Cold water & $82 \%$ & $2 \%$ \\
\hline Warm water & $1 \%$ & $93 \%$ \\
\hline Use soap/detergent/disinfectant & $15 \%$ & $5 \%$ \\
\hline \multicolumn{3}{|l|}{ Hands dried with paper/cloth before milking? } \\
\hline Yes & $27 \%$ & $23 \%$ \\
\hline \multicolumn{3}{|l|}{ Cleaning of udder and teats } \\
\hline \multicolumn{3}{|l|}{ Washed before milking? } \\
\hline Water only & $84 \%$ & $96 \%$ \\
\hline Soap/detergent/disinfectant & $4 \%$ & $1 \%$ \\
\hline \multicolumn{3}{|l|}{ Dried with paper/cloth before milking? } \\
\hline Yes & $14 \%$ & $25 \%$ \\
\hline \multicolumn{3}{|l|}{ Cleaning of milk utensils } \\
\hline \multicolumn{3}{|l|}{ How are milk utensils washed? } \\
\hline Water only & $81 \%$ & $60 \%$ \\
\hline Water + sand/ash & $0 \%$ & $6 \%$ \\
\hline Water + soap/detergent/disinfectant & $17 \%$ & $32 \%$ \\
\hline \multicolumn{3}{|l|}{ How often are the utensils washed? } \\
\hline Less than once a day & $4 \%$ & $8 \%$ \\
\hline Once daily & $20 \%$ & $8 \%$ \\
\hline More than once daily & $76 \%$ & $83 \%$ \\
\hline Before milking each new buffalo/cow & $0 \%$ & $1 \%$ \\
\hline \multicolumn{3}{|l|}{ Panel B: Food safety practices } \\
\hline How long does the milk stay on the farm before sales & $19 \min$ & $18 \mathrm{~min}$ \\
\hline \multicolumn{3}{|l|}{ Method of milk preservation before sales } \\
\hline 1) Not treated & $79.7 \%$ & \\
\hline 2) Boiling & $2.2 \%$ & \\
\hline 3) Refrigerating /chilling & $7 \%$ & \\
\hline 4) Cold water bath & $9.5 \%$ & \\
\hline 5) Other & $1.6 \%$ & \\
\hline
\end{tabular}


Table 3: Value chains and hygienic practices in Punjab and AP

\begin{tabular}{|c|c|c|}
\hline & $\begin{array}{l}\text { Number of } \mathrm{HH} \\
\text { in sample }\end{array}$ & $\begin{array}{c}\% \text { of dairy farmers } \\
\text { in sample }\end{array}$ \\
\hline \multicolumn{3}{|l|}{ 1. Hygienic practices } \\
\hline \multicolumn{3}{|c|}{ Panel A: Punjab } \\
\hline \multicolumn{3}{|c|}{ A.1. Received information on clean milk production } \\
\hline All sources & 8 & $1 \%$ \\
\hline From Nestlé & 4 & $0.5 \%$ \\
\hline From cooperative & 1 & $0.13 \%$ \\
\hline From government & 2 & $0.25 \%$ \\
\hline Other & 1 & $0.13 \%$ \\
\hline \multicolumn{3}{|c|}{ A.2. Received inspection on farm } \\
\hline All sources & 111 & $13.7 \%$ \\
\hline Inspection by milk buyer & 43 & $5.3 \%$ \\
\hline Inspection by government & 45 & $5.6 \%$ \\
\hline Other & 23 & $2.8 \%$ \\
\hline \multicolumn{3}{|c|}{ Panel B: AP } \\
\hline \multicolumn{3}{|c|}{ B.1. Received information on clean milk production } \\
\hline All sources & 26 & $3.3 \%$ \\
\hline From milk buyer (non-coop) & 2 & $0.3 \%$ \\
\hline From cooperative & 5 & $0.6 \%$ \\
\hline From government & 10 & $1.3 \%$ \\
\hline Other & 9 & $1.1 \%$ \\
\hline \multicolumn{3}{|c|}{ B.2. Received inspection on farm } \\
\hline All sources & 2 & $0.25 \%$ \\
\hline Milk buyer (non-coop) & 1 & $0.13 \%$ \\
\hline Other & 1 & $0.13 \%$ \\
\hline \multicolumn{3}{|c|}{ 2. Compound/mixed concentrates } \\
\hline \multicolumn{3}{|c|}{ Panel C: Punjab } \\
\hline \multicolumn{3}{|c|}{ C.1. Use compound/mixed concentrated feed } \\
\hline Yes & 437 & $54 \%$ \\
\hline \multicolumn{3}{|c|}{ C.2. Bought compound/mixed concentrated feed } \\
\hline All sources & 400 & $49.5 \%$ \\
\hline From Nestlé & 51 & $6.3 \%$ \\
\hline From cooperative & 29 & $3.6 \%$ \\
\hline From other private dairy & 17 & $2.1 \%$ \\
\hline General store & 235 & $29.1 \%$ \\
\hline Other & 68 & $8.4 \%$ \\
\hline \multicolumn{3}{|c|}{ C.3. Received information on improving milk quality through feeding } \\
\hline All sources & 9 & $1.1 \%$ \\
\hline From Nestlé & 4 & $0.5 \%$ \\
\hline From cooperative & 2 & $0.25 \%$ \\
\hline From government & 2 & $0.25 \%$ \\
\hline Other & 1 & $0.25 \%$ \\
\hline \multicolumn{3}{|l|}{ Panel D: AP } \\
\hline Continued on next page & & \\
\hline
\end{tabular}




\begin{tabular}{|c|c|c|}
\hline \multicolumn{3}{|c|}{ D.1. Use compound/mixed concentrated feed } \\
\hline Yes & 62 & $8 \%$ \\
\hline \multicolumn{3}{|c|}{ D.2. Bought compound/mixed concentrates } \\
\hline All sources & 53 & $6.6 \%$ \\
\hline From current milk buyer & 5 & $0.6 \%$ \\
\hline General store & 41 & $5.1 \%$ \\
\hline Other & 7 & $0.9 \%$ \\
\hline \multicolumn{3}{|c|}{ D.3. Subsidized compound/mixed concentrates } \\
\hline Offered by milk buyer & 91 & $11.4 \%$ \\
\hline Used by dairy farmer & 38 & $4.8 \%$ \\
\hline \multicolumn{3}{|l|}{ D.4. Free compound/mixed concentrates } \\
\hline Offered by milk buyer & 47 & $5.9 \%$ \\
\hline Used by dairy farmer & 16 & $2 \%$ \\
\hline \multicolumn{3}{|c|}{ D.5. Received information on improving milk quality through feeding } \\
\hline All & 31 & $3.9 \%$ \\
\hline From current milk buyer (non-coop) & 4 & $0.5 \%$ \\
\hline From cooperative & 7 & $0.9 \%$ \\
\hline From government & 7 & $0.9 \%$ \\
\hline Other & 13 & $1.6 \%$ \\
\hline \multicolumn{3}{|l|}{ 3. Graded/crossbred DA } \\
\hline \multicolumn{3}{|l|}{ Panel E: Punjab } \\
\hline \multicolumn{3}{|c|}{ E.1. Received information on improving milk quality through choice of breed } \\
\hline All sources & 8 & $1 \%$ \\
\hline From Nestlé & 2 & $0.25 \%$ \\
\hline From cooperative & 2 & $0.25 \%$ \\
\hline From private milk buyer & 1 & $1.3 \%$ \\
\hline From government & 2 & $0.25 \%$ \\
\hline Other & 1 & $1.3 \%$ \\
\hline \multicolumn{3}{|c|}{ E.2. Took a loan to finance purchase of crossbred cow } \\
\hline All & 0 & NA \\
\hline \multicolumn{3}{|c|}{ Panel F: AP } \\
\hline \multicolumn{3}{|c|}{ F.1. Received information on improving milk quality through choice of breed } \\
\hline All & 29 & $3.6 \%$ \\
\hline From current milk buyer (non-coop) & 3 & $0.3 \%$ \\
\hline From cooperative & 5 & $0.6 \%$ \\
\hline From government & 7 & $0.9 \%$ \\
\hline Other & 14 & $1.8 \%$ \\
\hline \multicolumn{3}{|c|}{ F.2. Took a loan to finance purchase of graded buffalo } \\
\hline All & 24 & $3 \%$ \\
\hline From cooperative & 1 & $0.13 \%$ \\
\hline From government & 1 & $0.13 \%$ \\
\hline Other & 22 & $2.7 \%$ \\
\hline \multicolumn{3}{|c|}{ F.3. Took a loan to finance purchase of crossbred cow } \\
\hline All & 14 & $1.8 \%$ \\
\hline From any type of milk buyer & 0 & 0 \\
\hline Other & 14 & $1.8 \%$ \\
\hline
\end{tabular}

Note: The numbers in panel F.2. and F.3. are higher when we look at all the HH that responded to the question. More precisely, of the $\mathrm{HH}$ that responded, $8.9 \%$ took a loan 
to finance the purchase of a graded buffalo and $9.7 \%$ for a crossbred cow (there were no differences for other questions).

Table 4: Dairy population

\begin{tabular}{lcccc}
\hline \hline & \multicolumn{2}{c}{ Punjab } & \multicolumn{2}{c}{ AP } \\
& Official & Sample & Official & Sample \\
\hline \% cows in DA population & 32 & 29 & 48 & 20 \\
\hline Cows desi & 15 & 5 & 67 & 67 \\
Cows crossbred & 85 & 95 & 33 & 33 \\
\hline \% buffalo in DA population & 68 & 71 & 52 & 80 \\
\hline Buffaloes desi & NA & 0 & 70 & 72 \\
Buffaloes graded & 100 & 100 & 30 & 28 \\
\hline$\%$ graded \& crossbred in population & 91 & 99 & 31 & 29 \\
\hline \hline
\end{tabular}

Source: Department of Animal Husbandry, government of India

Table 5: Dairy population and growth in sample

\begin{tabular}{lcccc}
\hline \hline & \multicolumn{2}{c}{ Punjab } & \multicolumn{2}{c}{ AP } \\
& Number & $\%$ increase & Number & $\%$ increase \\
& 2008 & $2003-2008$ & 2010 & $2005-2010$ \\
\hline Total cows & 997 & $+11 \%$ & 502 & $+27 \%$ \\
\hline Cows desi & 50 & $-2 \%$ & 335 & $+43 \%$ \\
Cows crossbred & 947 & $+12 \%$ & 167 & $+4 \%$ \\
\hline Total buffaloes & 2458 & $+12 \%$ & 1991 & $+55 \%$ \\
\hline Buffaloes desi & 0 & 0 & 1436 & $+12 \%$ \\
Buffaloes graded & 2458 & $+12 \%$ & 555 & $+70 \%$ \\
\hline Total all types & 3455 & $+12 \%$ & 2493 & $+24 \%$ \\
\hline \hline
\end{tabular}

Table 6: Correlations between the technology adoption indicators

\begin{tabular}{|c|c|c|c|c|c|c|}
\hline & \multicolumn{3}{|c|}{ Punjab } & \multicolumn{3}{|c|}{ AP } \\
\hline & $\begin{array}{l}\text { Hygiene } \\
\text { Index }\end{array}$ & $\begin{array}{l}\text { Dummy } \\
\text { compound/ } \\
\text { mixed } \\
\text { concentrate }\end{array}$ & $\begin{array}{c}\text { Share } \\
\text { crossbred }\end{array}$ & $\begin{array}{l}\text { Hygiene } \\
\text { Index }\end{array}$ & $\begin{array}{l}\text { Dummy } \\
\text { compound/ } \\
\text { mixed } \\
\text { concentrate }\end{array}$ & $\begin{array}{c}\text { Share } \\
\text { graded/ } \\
\text { crossbred }\end{array}$ \\
\hline $\begin{array}{l}\text { Hygiene Index } \\
\text { Dummy } \\
\text { compound/mixed } \\
\text { concentrate } \\
\text { Share } \\
\text { graded/crossbred }\end{array}$ & $\begin{array}{l}0.00 \\
0.02\end{array}$ & $\begin{array}{c}1 \\
0.13\end{array}$ & 1 & 0.08 & $\begin{array}{c}1 \\
0.02\end{array}$ & 1 \\
\hline
\end{tabular}




\begin{tabular}{|c|c|c|c|}
\hline & Hygiene index & $\begin{array}{c}\text { Dummy } \\
\text { compound/mixed } \\
\text { concentrates }\end{array}$ & Share crossbred \\
\hline \multicolumn{4}{|l|}{ Supply chain: HH sells to } \\
\hline Cooperative & $\begin{array}{c}0.013 \\
(0.020)\end{array}$ & $\begin{array}{c}0.279 \\
(0.236)\end{array}$ & $\begin{array}{l}0.078 * \\
(0.040)\end{array}$ \\
\hline Private domestic & $\begin{array}{l}-0.000 \\
(0.025)\end{array}$ & $\begin{array}{c}0.488 \\
(0.306)\end{array}$ & $\begin{array}{c}0.066 \\
(0.042)\end{array}$ \\
\hline Private foreign (Nestlé) & $\begin{array}{c}0.041 * * \\
(0.019)\end{array}$ & $\begin{array}{c}0.168 \\
(0.276)\end{array}$ & $\begin{array}{c}0.151^{* * * *} \\
(0.044)\end{array}$ \\
\hline No sales & $\begin{array}{c}-0.008 \\
(0.020) \\
\end{array}$ & $\begin{array}{c}-0.262 \\
(0.259) \\
\end{array}$ & $\begin{array}{c}0.049 \\
(0.035) \\
\end{array}$ \\
\hline \multicolumn{4}{|l|}{ Income } \\
\hline Total income & $\begin{array}{l}0.026^{*} \\
(0.014)\end{array}$ & $\begin{array}{l}-0.045 \\
(0.083)\end{array}$ & $\begin{array}{l}-0.017 \\
(0.020)\end{array}$ \\
\hline Income dairy & $\begin{array}{c}-0.016 \\
(0.013) \\
\end{array}$ & $\begin{array}{c}0.047 \\
(0.129) \\
\end{array}$ & $\begin{array}{c}0.026 \\
(0.024) \\
\end{array}$ \\
\hline \multicolumn{4}{|l|}{ Farm size } \\
\hline Herd size & $\begin{array}{c}0.002 \\
(0.002)\end{array}$ & $\begin{array}{c}0.083 * * \\
(0.042)\end{array}$ & $\begin{array}{c}0.021 * * * \\
(0.004)\end{array}$ \\
\hline Land owned & $\begin{array}{l}-0.011 \\
(0.010)\end{array}$ & $\begin{array}{c}0.116 \\
(0.082)\end{array}$ & $\begin{array}{c}-0.034 * * \\
(0.016)\end{array}$ \\
\hline \multicolumn{4}{|l|}{ Household Characteristics } \\
\hline Education $\mathrm{HH}$ head & $\begin{array}{c}0.002 \\
(0.002)\end{array}$ & $\begin{array}{c}0.008 \\
(0.013)\end{array}$ & $\begin{array}{c}0.005 \\
(0.003)\end{array}$ \\
\hline Age HH head & $\begin{array}{l}-0.000 \\
(0.001)\end{array}$ & $\begin{array}{c}0.005 \\
(0.005)\end{array}$ & $\begin{array}{c}0.001 \\
(0.001)\end{array}$ \\
\hline $\mathrm{SC} / \mathrm{ST}$ & $\begin{array}{l}-0.010 \\
(0.017) \\
\end{array}$ & $\begin{array}{c}0.025 \\
(0.190) \\
\end{array}$ & $\begin{array}{l}-0.029 \\
(0.042) \\
\end{array}$ \\
\hline Other HH Characteristics & YES & YES & YES \\
\hline District fixed effects & YES & YES & YES \\
\hline Observations & 766 & 771 & 771 \\
\hline R-squared & 0.084 & NA & 0.176 \\
\hline
\end{tabular}

Notes: All regressions are run at the HH level and include a set of district dummies. The share of crossbred DA indicates the number of crossbred DA over total herd size. SC/ST indicates if a household belongs to a scheduled caste or tribe. Robust standard errors (clustered at the village level) in parentheses. $* \mathrm{p}<0.1, * * \mathrm{p}<0.05, * * * \mathrm{p}<0.01$. 


\begin{tabular}{|c|c|c|c|}
\hline & Hygiene index & $\begin{array}{c}\text { Dummy } \\
\text { compound/mixed } \\
\text { concentrates }\end{array}$ & $\begin{array}{c}\text { Share } \\
\text { graded/crossbred }\end{array}$ \\
\hline \multicolumn{4}{|l|}{ Supply chain: $\mathrm{HH}$ sells to } \\
\hline Cooperative & $\begin{array}{l}-0.017 \\
(0.024)\end{array}$ & $\begin{array}{c}0.056 \\
(0.203)\end{array}$ & $\begin{array}{c}-0.119 * * \\
(0.058)\end{array}$ \\
\hline Private domestic & $\begin{array}{l}-0.024 \\
(0.021)\end{array}$ & $\begin{array}{c}0.132 \\
(0.274)\end{array}$ & $\begin{array}{l}-0.016 \\
(0.054)\end{array}$ \\
\hline No sales & $\begin{array}{c}-0.074 * * * \\
(0.024)\end{array}$ & $\begin{array}{l}-0.159 \\
(0.296)\end{array}$ & $\begin{array}{l}-0.006 \\
(0.053)\end{array}$ \\
\hline \multicolumn{4}{|l|}{ Income } \\
\hline Total income & $\begin{array}{l}-0.006 \\
(0.007)\end{array}$ & $\begin{array}{c}-0.013 \\
(0.111)\end{array}$ & $\begin{array}{c}0.001 \\
(0.018)\end{array}$ \\
\hline Income dairy & $\begin{array}{c}0.022 * * \\
(0.009)\end{array}$ & $\begin{array}{c}0.261 * * \\
(0.108)\end{array}$ & $\begin{array}{c}0.086^{* * * *} \\
(0.022)\end{array}$ \\
\hline \multicolumn{4}{|l|}{ Farm size } \\
\hline Herd size & $\begin{array}{c}-0.004 * \\
(0.003)\end{array}$ & $\begin{array}{l}-0.002 \\
(0.030)\end{array}$ & $\begin{array}{l}-0.004 \\
(0.008)\end{array}$ \\
\hline Land owned & $\begin{array}{c}0.024 * * * \\
(0.008)\end{array}$ & $\begin{array}{l}-0.107 \\
(0.106)\end{array}$ & $\begin{array}{c}-0.046^{*} \\
(0.025)\end{array}$ \\
\hline \multicolumn{4}{|l|}{ Household Characteristics } \\
\hline Education $\mathrm{HH}$ head & $\begin{array}{c}-0.001 \\
(0.001)\end{array}$ & $\begin{array}{l}-0.014 \\
(0.017)\end{array}$ & $\begin{array}{c}0.011 * * * \\
(0.003)\end{array}$ \\
\hline Age HH head & $\begin{array}{c}-0.002 * * \\
(0.001)\end{array}$ & $\begin{array}{l}-0.010 \\
(0.006)\end{array}$ & $\begin{array}{c}0.005 * * * \\
(0.001)\end{array}$ \\
\hline $\mathrm{SC} / \mathrm{ST}$ & $\begin{array}{l}-0.014 \\
(0.022)\end{array}$ & $\begin{array}{l}-0.133 \\
(0.319)\end{array}$ & $\begin{array}{c}0.130 * * \\
(0.052)\end{array}$ \\
\hline Other HH Characteristics & YES & YES & YES \\
\hline District fixed effects & YES & YES & YES \\
\hline Observations & 707 & 726 & 726 \\
\hline R-squared & 0.244 & NA & 0.379 \\
\hline
\end{tabular}

Notes: All regressions are run at the HH level and include a set of district dummies. The share of graded/crossbred DA indicates the number of graded/crossbred DA over total herd size. SC/ST indicates if a household belongs to a scheduled caste or tribe. Robust standard errors (clustered at the village level) in parentheses. $* \mathrm{p}<0.1, * *$ $\mathrm{p}<0.05, * * * \mathrm{p}<0.01$ 